\title{
A pessoa como sujeito de direitos na sociedade da informação: teletrabalho como forma de inclusão social - um desafio
}

\author{
The person as a subject of rights in the information \\ society: telework as a means of social inclusion - a \\ challenge
}

\author{
Maria Cristina Cereser Pezzella* \\ Michelle Dias Bublitz*
}

\section{Resumo}

A sociedade da informação diferencia-se por meio da inovação e da instantaneidade, caracterizando-se pela velocidade no acesso e troca de informações. As tradicionais formas de prestação de serviços, aos poucos, vão cedendo espaço a novas relações contratuais que não exigem a presença física do trabalhador, como o teletrabalho, o qual revela uma mudança de paradigma manifestada em um novo ambiente de trabalho, descentralizado dos centros de produção e centralizado no conhecimento e na informação. O teletrabalho surge como uma realidade laboral disseminada como promissora ao gerar novos empregos, manter os existentes e regularizar a situação dos trabalhadores que

Doutora em Direito pela Universidade Federal do Paraná - UFPR (2002). Mestre em Direito pela Universidade Federal do Rio Grande do Sul - UFRGS (1998). Graduada em Direito pela Pontifícia Universidade Católica do Rio Grande do Sul - PUCRS (1988). Professora da Pós-Graduação em Direito da Universidade do Oeste de Santa Catarina - UNOESC. Coordenadora/líder do grupo de pesquisas (CNPq) intitulado "Direitos Fundamentais Civis: A Ampliação dos Direitos Subjetivos" - UNOESC. Avaliadora do INEP/MEC e Supervisora do SESu/MEC. Advogada. Chapecó - SC Brasil. E-mail: crispezzella@uol.com.br

* Mestre em Direito pela Pontifícia Universidade Católica do Rio Grande do Sul - PUCRS (2014). Especialista em Direito e Processo do Trabalho pela Faculdade IDC - Instituto de Desenvolvimento Cultural (2009). Graduada em Direito pela Universidade Luterana do Brasil - ULBRA - campus Canoas/RS (2008). Integrante qualificada como pesquisadora do grupo de estudos e pesquisas (CNPq) intitulado "Novas Tecnologias e Relações de Trabalho", sob coordenação da Profa. Dra. Denise Pires Fincato, sediado na PUCRS. Porto Alegra - RS - Brasil. E-mail: michellebublitz@ gmail.com 
se encontram à margem da lei. Ponderando-se tais questões, o teletrabalho é, por fim, analisado - principalmente na sua modalidade desenvolvida nas residências dos trabalhadores - sob a ótica jurídico-social, na medida em que as tecnologias da informação e comunicação, ferramentas indispensáveis para a consecução dessa modalidade de prestação de serviço, podem ser, para alguns, a mola propulsora da inserção ao mercado de trabalho e, para outros, geradora de exclusão laboral e social.

Palavras-chave: Pessoa humana. Sujeito de direitos. Sociedade da informação. Teletrabalho. Inclusão social.

\section{Abstract}

The Information Society differentiates itself through innovation and immediacy, characterized by the speed of access and information exchange. The traditional ways of providing services are slowly giving way to new contractual relationships that do not require the physical presence of the worker, such as teleworking, which reveals a paradigm shift manifested in a new working environment of decentralized production centers and centralized in knowledge and information. Teleworking employment emerges as a widespread reality as promising to create new jobs, retain existing and regularize the situation of workers who find themselves outside the law. Weighing up these issues, telecommuting is finally analyzed - especially in its developed form in the homes of workers under the legal and social perspective, insofar as information technology and communication tools necessary for achieving this type of service delivery and work may be at the same time, the springboard for some of the insertion to the labor market and other generator of employment and social exclusion.

Keywords: Human person. Subject of rights. Information Society. Teleworking. Social inclusion.

\section{Introdução}

O trabalho modificou-se ao longo do tempo, na medida em que as tecnologias de informação e comunicação se tornaram um elemento indissociável do desenvolvimento da atividade econômica, constituindose em um fator cada vez mais importante na organização e estruturação das sociedades modernas. Do atual trabalhador, são exigidos 
conhecimentos cada vez mais complexos, habilidades diferenciadas e maior qualificação profissional.

As tradicionais formas de prestação de serviços, aos poucos, vão cedendo espaço às novas relações contratuais, as quais não exigem a presença física do trabalhador, como o teletrabalho, um dos objetos da presente pesquisa, propulsor do processo econômico da descentralização produtiva, que anda de mãos dadas com a globalização e flexibilização das relações de emprego.

O teletrabalho, diante de suas características conceituais e estruturais altamente polêmicas, compõe debates sobre sua existência, estruturação, organização, manutenção, aplicação ou extinção, e fomenta relevantes pesquisas. Não se pode negar a inafastável necessidade de se questionar os efeitos, as vantagens e desvantagens.

Das peculiaridades observadas para esse tipo de prestação de serviços, destaca-se como principal vantagem a ausência de deslocamento do empregado até o local de trabalho. Entretanto, as vantagens podem revestir-se de desvantagens para alguns trabalhadores, ao trazer a questão do isolamento social ou da escravidão digital.

O sistema constitucional de proteção do direito ao trabalho começa pela inquestionável essencialidade do labor na vida do ser humano, não só por se tratar da forma pela qual este obtém parte do necessário à sua subsistência e assegura o direito à dignidade da pessoa humana, mas por ser instrumento de realização pessoal do indivíduo, tornando-o respeitável perante a sociedade e, principalmente, cidadão, possuidor de direitos e obrigações.

Nesse sentido, destaca-se como princípio basilar dessa iniciativa o princípio constitucional da igualdade, como resposta à necessidade de conferir efetividade ao direito ao trabalho, pois, por considerar positivamente as diferenças humanas, é o verdadeiro alicerce de todos os direitos constitucionalmente conferidos aos trabalhadores. Esta pesquisa evidencia a importância da inclusão social através da inserção no mercado de trabalho, tema de grande relevância. 


\section{Surgimento da pessoa como sujeito de direitos}

Inicialmente, faz-se necessário delimitar o momento histórico ${ }^{1}$ e percorrer o conteúdo e o significado que a pessoa humana adquire quando nasce como sujeito de direitos, para, em seguida, compreender a importância do trabalho como essencialidade na vida do sujeito.

$\mathrm{Na}$ antiguidade clássica, a ideia de dignidade da pessoa humana relacionava-se com a posição social ocupada pelo indivíduo e o seu grau de reconhecimento pelos demais membros da comunidade. Por essa razão, naquele momento histórico, era possível falar em quantificação e modulação da dignidade, compreendendo-se, inclusive, a existência de pessoas mais dignas do que outras, segundo Podlech (1989 apud SARLET, 2011, p. 35).

Anteriormente ao reconhecimento de todas as pessoas como sujeitos de direitos e obrigações, sequer poderia ser conferida à expressão "dignidade da pessoa humana" uma compreensão que pudesse abranger a todos, pois alguns ainda estavam na seara de serem considerados objetos dos outros. Não se restringe essa compreensão a um passado muito distante, quando nem todos eram considerados cidadãos, pois houve momentos ainda próximos no tempo em que as pessoas tiveram sua capacidade restringida, e em algumas sociedades contemporâneas ainda são gravadas uma série de injustificáveis e inadmissíveis restrições.

O surgimento da discussão a respeito do direito subjetivo só tem razão de existir quando se tem o reconhecimento político, social e jurídico da pessoa humana como sujeito de direitos a ser protegido e tutelado nas relações com o Estado e entre os particulares.

O pensamento de Michel Villey a respeito dos direitos subjetivos e sua crítica aos direitos humanos não são muito conhecidos, mas, de certo

No que toca ao aspecto da investigação histórica, seguimos o pensamento de Michel Villey, fundado nas palestras desenvolvidas pelo autor na Universidade de Valparaíso, posteriormente publicadas sob o título Estudios en torno a la noción de derecho subjetivo, com tradução de Alejandro Guzmán Brito e outros, Chile: Ediciones Universitarias de Valparaiso, 1976. 
modo, são muito propícios para que se tenha em mente a realização dos direitos fundamentais e da dignidade da pessoa humana. Compreender essa discussão que se travou na história implica compreender melhor a evolução do que inicialmente se chamou de direitos humanos e quais as razões jurídicas que levaram a uma transmutação não apenas na esfera semântica, mas também na expectativa política, social e jurídica de efetividade da proteção dos direitos lesados ou ameaçados de lesão. Sujeito de direitos e deveres são, portanto, na compreensão de Villey (1976, p. 17-18), conforme descreve Alejandro Guzmán Brito, assim:

En efecto, según Villey, la noción de derecho subjetivo tenía que nacer como tal, entre aquellos filósofos que a fines de la Edad Media y en la Época Moderna han emprendido una lucha contra la filosofía aristotélico-tomista; contra esa filosofía objetivista y realista, la escuela nominalista y la moderna oponen un mundo de individuos aislados entre sí, que sólo se interconexionan por el nombre común pero no por esencias o naturalezas comunes. Al orden del derecho natural clásico, al carácter natural de la Sociedad de que aquél partía, los modernos oponen el estado pre social, también natural, pero en donde lo natural deja de ser precisamente la Sociedad y pasa a ser el individuo con sus plenas libertades y poderes. Porque hay que hacer notar que la doctrina del derecho subjetivo nace y se desarrolla también como una doctrina del derecho natural; sólo que si en la concepción antigua el derecho natural era lo justo objetivo, de modo que misión del derecho positivo era la determinación de la parte justa de cada cual, en la doctrina del derecho subjetivo lo natural son precisamente los derechos subjetivos: el hombre, y sus derechos aislado y en contra de todos los demás hombres, constituirá un estado natural; $y$ aunque a dicho estado se ha superpuesto un pacto social, las exigencias del individuo siguen siendo la fuente de los derechos subjetivos, que deben ser analizadas por el jurista y el legislador con el fin de determinar los derechos de cada cual. De acuerdo con este modo de pensar, el dominio, $p$. ej., ya no será más la parte justa de cosas repartidas entre todos, sino que el poder mismo que se ejerce sobre las cosas en propio provecho. 
A essência do pensamento de Michel Villey consiste em advogar a tese de que o direito antigo não conheceu a ideia de direito subjetivo, a qual tem origem moderna. Na busca pela origem dos direitos subjetivos, o autor realiza uma investigação histórica e filosófica, passando a compreender que as pessoas com necessidade de defender-se e salvaguardar-se das atividades do Poder Público podem encontrar o conjunto de elementos que teriam sido propícios para o nascimento da noção de direito subjetivo.

Villey (1976) busca conferir os contornos dessa nova forma de compreender o direito a partir do ponto de vista subjetivo, vale referir, da pessoa sujeito de direitos, detentora de faculdades e escolhas (e deveres), e não mais da concepção objetiva, em que os papéis sociais estavam previamente delimitados e estratificados frente a variáveis muito pouco alteráveis.

Como as relações jurídicas se travam entre pessoas desiguais, o Estado deve atuar de maneira a reequilibrar as relações no plano concreto dos fatos que se desenvolvem no cotidiano.

A importância que a sociedade confere à dignidade da pessoa humana nas relações pessoais e com o macrossistema da cultura social e jurídica, enfrentando a sua repercussão concreta e efetiva, está imbricada com a potencialidade que se atribui à capacitação de quem compõe, em última análise, a sociedade.

A dignidade é, essencialmente, um atributo da pessoa humana. Pelo simples fato de ser humana, a pessoa merece respeito, independentemente de sua origem, raça, sexo, idade, estado civil ou condição social e econômica. Nesse sentido, o conceito de dignidade da pessoa humana não pode ser relativizado.

Quanto mais protegida a dignidade da pessoa humana, mais desenvolvida culturalmente a sociedade e mais próxima de uma realização efetiva das possibilidades de seus formadores.

Uma sociedade que não perquire, não discute e não confere possibilidades para uma ampla discussão social e jurídica sobre a 
importância da pessoa em sua plenitude deixa de cumprir o seu principal papel: o desenvolvimento integral do indivíduo.

Sabe-se que a ideia de "ser sujeito" não apenas revela uma capacidade de pensar, agir e se relacionar com o mundo físico e social, como também define nossa condição de portadores de direitos. Mas o que significa ter direito e a que tipo de direito nos referimos? A ideia de direito possui vários sentidos. Sua significação tanto pode estar relacionada à noção de natureza humana, como o direito à vida, à saúde, à moradia e ao trabalho, quanto pode estar ligada ao mundo da política e à esfera do Estado, sob a forma de princípios legais destinados a garantir e defender a dignidade humana.

\section{O direito à igualdade face ao princípio da dignidade da pessoa humana}

O exame dos princípios fundamentais do Estado brasileiro, para Silva Neto (2005), deve preceder o estudo da incorporação dos direitos fundamentais ao contrato de trabalho, em razão de que tais postulados servem de "vetores interpretativos" da própria Constituição e da legislação trabalhista.

Para Queiroz Júnior (2006, p. 85), o princípio da dignidade da pessoa humana deve ser considerado como fundamento de todo o sistema de direitos fundamentais, pois estes se constituem em "exigências, concretizações e desdobramentos da dignidade da pessoa humana e com fundamento nesta devem ser interpretados".

Romita (2007) chama atenção para um paradoxo: nos estudos sobre relações de trabalho, quase não se vê referência aos direitos humanos, embora o obreiro seja uma pessoa que não deixa de ter tal condição quando inserido no âmbito da relação empregatícia.

A questão da incidência dos direitos fundamentais nas relações de emprego possui clara e indiscutível justificativa: o objeto da relação de emprego é o trabalho, e não o trabalhador. Resta impossível desmembrar 
tais figuras, motivo pelo qual este detém a proteção dos direitos fundamentais como cidadão e, especificamente, como trabalhador. Conclui-se que os direitos fundamentais ocupam papel importante no ordenamento jurídico pátrio, configurando-se como parâmetro dentro do qual devem ser interpretadas todas as normas trabalhistas (GÓES, 2009).

Existem situações concretas que se configuram como nítidos desdobramentos da aplicação dos direitos fundamentais nas relações de emprego, considerando o caráter de pessoa humana do trabalhador.

O princípio da dignidade da pessoa humana traz consigo a inquestionável essencialidade do labor na vida do ser humano, não só por se tratar da forma pela qual este obtém boa parte do necessário à sua subsistência, mas por ser instrumento de realização pessoal do indivíduo, tornando-o respeitável perante a sociedade e, principalmente, incluindo-o como cidadão, possuidor de direitos e deveres.

Nessa esteira de raciocínio, pode-se afirmar que o sistema constitucional de proteção ao direito ao trabalho começa pelo princípio da igualdade, o qual vem insculpido no caput do artigo $5^{\circ}$ da Constituição Federal de 1988, ou seja, à frente de todos os direitos e garantias fundamentais, orientando a interpretação a ser conferida aos direitos e deveres individuais e coletivos.

Adoutrina trata do princípio da igualdade juntamente com o princípio da não discriminação, tendo em vista o natural liame que possuem. $O$ princípio da igualdade nada mais faz do que ventilar situações, de forma que as pessoas compreendidas venham a ser tratadas por critérios diferentes e, para alguns, sejam deferidos determinados direitos e obrigações que não assistem outros. Os pontos para discriminar determinadas situações devem ser decorrentes de aptidões pessoais, e não de critérios individuais personalíssimos. O Direito do Trabalho foi a primeira ação afirmativa historicamente consolidada nessa perspectiva.

Todas as pessoas são singulares, mas iguais em direitos, o que não confere o direito de serem tratadas de forma a ferir o princípio da 
igualdade, o qual está ancorado no princípio da dignidade da pessoa humana.

Na sociedade da informação, surgiu uma modalidade diferente de trabalho, denominada teletrabalho. Por isso, torna-se necessário compreender os aspectos doutrinários relevantes, com o intuito de resolver os casos concretos.

\section{Teletrabalho: compreensão doutrinária}

O trabalho possui uma valoração entre os seres humanos. Essa valoração flutuou muito ao longo da história. Inicialmente tido como natural e para consumo próprio (Pré-História), posteriormente, viria a traduzir-se em instrumento de dominação ou poder (escravidão, servidão e vassalagem, por exemplo), atrelando-se à ideia de desmerecimento social e até de castigo. Com a intensificação do uso das tecnologias de comunicação e informação, novas formas de relacionamento laboral se inauguram e, com isso, a realidade atual revela uma mudança de paradigma, manifestada em um novo ambiente de trabalho, descentralizado dos centros de produção e centralizado no conhecimento e na informação, não se exigindo a presença física do trabalhador - no caso, o teletrabalho².

A paternidade do termo "teletrabalho" é atribuída a Nilles (1997), que assim teria definido qualquer forma de substituição de deslocamentos relacionados com a atividade econômica por tecnologias da informação, ou a possibilidade de enviar o trabalho ao trabalhador em vez de enviar o trabalhador ao trabalho.

Fincato (2003, p. 41) afirma que "o teletrabalho constitui-se em modalidade surgida dessa revolução informacional, que mescla os avanços tecnológicos (principalmente informáticos) e comunicacionais".

No que toca ao aspecto do estudo do teletrabalho, seguimos, como referência, o pensamento do grupo de pesquisas (CNPq) intitulado "Novas Tecnologias e Relações de Trabalho", da PUCRS, coordenado pela Profa. Dra. Denise Pires Fincato. 
O conceito tradicional da Organização Internacional do Trabalho (GBEZO, 1995) descreve o teletrabalho como o que é efetuado distante dos escritórios centrais ou das oficinas de produção, mas com os trabalhadores mantendo-se conectados com alguns de seus colegas por meio das novas tecnologias ${ }^{3}$.

O teletrabalho pode ser realizado em domicílio, telecentros, centros satélites, telecottages ou não ter um espaço definido, como é o caso do teletrabalho nômade ou móvel. Dentre as modalidades citadas, destaca-se, para este estudo, o teletrabalho no domicílio do empregado. Por vezes, o teletrabalho é comparado com o trabalho em domicílio, pois tanto um quanto o outro são espécies de trabalho a distância, conforme alude Pedreira (2000).

No teletrabalho em domicílio, o trabalhador realiza sua atividade na própria residência ou em ambiente familiar, com ajuda de mecanismos telemáticos ${ }^{4}$. É importante salientar que a falta de uso de formas telemáticas de serviço acabariam por descaracterizar o teletrabalho em domicílio, passando a ser considerado trabalho em domicílio normal (SILVA, 2004) $)^{5}$. Portanto, observa-se a relação entre a utilização ou não de tecnologias de informação e comunicação, para não confundir teletrabalho com trabalho em domicílio.

3 Em sentido semelhante, ver: DE MASI, Domenico. O futuro do trabalho: fadiga e ócio na sociedade pós- industrial. Rio de Janeiro: José Olímpio, 1999. PEDREIRA, José Pinho. O teletrabalho. Revista LTr, São Paulo, v. 64, n. 5, maio 2000.

4 Telemática é a comunicação a distância de um conjunto de serviços informáticos fornecidos por meio de uma rede de telecomunicações. É o conjunto de tecnologias de transmissão de dados resultante da junção entre os recursos das telecomunicações (telefonia, satélite, cabo, fibras ópticas etc.) e da informática (computadores, periféricos, softwares e sistemas de redes), que possibilitou o processamento, a compressão, o armazenamento e a comunicação de grandes quantidades de dados (nos formatos de texto, imagem e som), em curto prazo de tempo, entre usuários localizados em qualquer ponto do planeta. A telemática pode ser definida como a área do conhecimento humano que reúne um conjunto e o produto da adequada combinação das tecnologias associadas à eletrônica, informática e telecomunicações, aplicadas aos sistemas de comunicação e sistemas embarcados, caracterizando-se pelo estudo das técnicas para geração, tratamento e transmissão da informação, sendo preservadas as características de ambas, porém, apresentando novos produtos derivados delas.

5 No campo normativo, o teletrabalhador em domicílio equipara-se ao trabalhador em domicílio normal, regulamentado pelo artigo $6^{\circ}$ da Consolidação das Leis Trabalhistas. 
No seu domicílio ${ }^{6}$, o empregado pode ser monitorado/controlado pela empresa com a qual mantém contrato de trabalho. O monitoramento deve ser feito virtual ou presencialmente, através das novas tecnologias desenvolvidas para isso (como sistema de logins e biometria).

Dessa forma, a inovação tecnológica subverte a relação de trabalho clássica, sendo responsável por novos tipos de atividades, descentralizadas e que reúnem informação e comunicação (BARROS, 2009). Essa prática vem sendo observada, em escala razoável, nos países que já desenvolveram a tecnologia virtual em níveis que permitem considerá-los integrados à chamada era pós-industrial do trabalho.

A título de direito comparado, há países que definiram juridicamente e regulamentaram o teletrabalho, tais como: Itália, Espanha, Portugal e Chile. Destaca-se o Acordo Europeu sobre Teletrabalho, que, como o próprio nome já refere, é um acordo entre os países integrantes do Conselho Europeu, o qual estabelece um parâmetro geral para internalização legislativa no tocante ao teletrabalho.

O teletrabalho aparece como uma nova modalidade de prestação de serviços, sem cobertura legal específica no Brasil. Até o momento, sua definição não responde a critérios jurídicos, mas, sim, a considerações práticas. No anseio de regulamentar a questão, o Brasil depara-se, atualmente, com alguns Projetos de Lei em tramitação.

O Projeto de Lei $n^{\circ} 3.129 / 2004$, de autoria do deputado Eduardo Valverde, pertencente ao Partido dos Trabalhadores (PT) de Rondônia, recebeu parecer favorável dos integrantes da Câmara dos Deputados e foi remetido ao Senado Federal, sob o $n^{\circ} 102 / 2007$, para posterior apreciação. O Projeto de Lei $n^{\circ} 102 / 2007$ tem por finalidade equiparar os efeitos jurídicos da subordinação exercida por meios telemáticos e informatizados à exercida por meios pessoais e diretos, a partir da

6 Também conhecido como homesourcing (FRIEDMAN, 2009). 
alteração da redação do artigo $6^{\circ}$ da Consolidação das Leis do Trabalho (CLT), o qual passaria a abranger expressamente os teletrabalhadores ${ }^{7}$.

Ao justificar sua iniciativa, o autor da proposição afirma que a evolução tecnológica e as mutações do trabalho exigem permanentes transformações da ordem jurídica, com o intuito de apreender a realidade variável. O tradicional comando direto entre o empregador e o empregado, hoje, cede lugar ao comando a distância, mediante o uso de meios telemáticos. Neste, o empregado sequer sabe quem é o emissor da ordem de comando e controle ${ }^{8}$.

O Projeto de Lei $n^{\circ} 4.505 / 2008$, de autoria do deputado Luiz Paulo Vellozo Lucas, pertencente ao Partido da Social Democracia Brasileira (PSDB) do Espírito Santo, diferentemente do Projeto de Lei antes mencionado, pretende regulamentar o trabalho a distância, além de conceituar e disciplinar as relações de teletrabalho. O Projeto foi aprovado, mas pendente de recurso.

A partir das premissas apontadas, vê-se que, apesar de haver iniciativas e projetos de leis, não existe um real e comprometido empenho do parlamento brasileiro para regulamentar a matéria de forma eficiente, imediata e sistemática. A pouca conceituação de teletrabalho existente é um reflexo da falta de legislação específica sobre o tema, no entanto, utiliza-se do princípio do contrato-realidade e de alguns dispositivos legais que analogicamente se amoldam a esse tipo de organização de trabalho a fim de que se possa caracterizar ou não a relação de emprego.

Na perspectiva de melhor compreender os limites e as formas de proteção das pessoas que vinculam sua força de trabalho remunerada à

$7 \quad 0$ artigo $6^{\circ}$ da CLT, se aprovado o Projeto de Lei, passaria a vigorar sob a seguinte redação: "Art. $6^{\circ}$. Não se distingue entre trabalho realizado no estabelecimento do empregador, o executado no domicílio do empregado e o realizado a distância, desde que estejam caracterizados os pressupostos da relação de emprego. Parágrafo único. Os meios telemáticos e informatizados de comando, controle e supervisão se equiparam, para fins de subordinação jurídica, aos meios pessoais e diretos de comando, controle e supervisão do trabalho alheio."

8 Justificativa contida no Parecer, de relatoria do Senador Cristovam Buarque. Disponível em: <http://www.senado.gov.br/atividade/materia/getPDF.asp?t=22949>. Acesso em: 30 jun. 2010. 
execução laboral via teletrabalho, faz-se necessário caracterizar como relação de emprego.

\subsection{Caracterização da relação de emprego no teletrabalho}

A prestação de serviços na modalidade teletrabalho cria, necessariamente, um contrato expresso, que pode ser escrito ou verbal, ou tácito, o qual, se contemplar os requisitos previstos nos artigos $2^{\circ}$ e $3^{\circ}$ da CLT, ter-se-á um teletrabalho com características de relação de emprego e sujeito às regras da legislação trabalhista. Se o contrato firmado entre as partes não contiver os requisitos caracterizadores da relação de emprego, provavelmente estar-se-á diante de uma relação de trabalho autônoma.

No caso de configuração da relação de emprego, não há como desconsiderar os cinco elementos que a caracterizam: prestação de serviços por pessoa física, de forma pessoal, não eventual, subordinada e mediante salário.

O requisito da pessoalidade e o da pessoa física quer dizer que o contrato é realizado em razão das qualificações pessoais do empregado, ou seja, é intuitu personae, não admitindo substituição do contratado. A pessoalidade no contrato de teletrabalho acaba por ser mitigada, passando do caráter de trabalho pessoal para trabalho de responsabilidade pessoal. Entretanto, o teletrabalho, até mesmo pela sua natureza de utilizar meios telemáticos, quase sempre informáticos, dispõe ao empregado artifícios tecnológicos, como senhas pessoais de sua inteira responsabilidade, chamadas de assinaturas eletrônicas, uso da biometria, entre outras possibilidades que validam sua identidade e pessoalidade perante o empregador (SOARES JÚNIOR, 2004)

Outro requisito do contrato de trabalho é a habitualidade, a continuidade na prestação de serviços, posto que o pacto firmado entre as partes na modalidade relação de emprego constitui contrato de trato sucessivo, que não se exaure em uma única prestação (MARTINS, 2008). Segundo Fincato (2003), no teletrabalho, a habitualidade deve ser medida pelos contatos que o teletrabalhador mantém com o 
empregador, prestando-Ihe contas, enviando-Ihe serviços e recebendo diretrizes. Esse elemento é decorrência do princípio da continuidade da relação de emprego (OLIVEIRA, 2008). Por esse princípio, presume-se a permanência indefinida do vínculo empregatício.

O requisito da onerosidade encontra-se disposto no artigo 83 da CLT, utilizado analogicamente ao contrato de teletrabalho por falta de regulamentação especifica, em que é devida uma remuneração mensal mínima ao trabalhador, sem qualquer discriminação em relação ao trabalhador presencial.

No que concerne à subordinação, diz-se que esta é o mais importante elemento para demonstrar o vínculo jurídico existente na relação de emprego, servindo, inclusive, de base para toda a normatização jurídico-trabalhista (PINO ESTRADA, 2004). Tradicionalmente, existem vários critérios de subordinação, entre eles, o da subordinação econômica, social, técnica e jurídica. A subordinação jurídica se destaca, pois enfatiza o estado de dependência real do empregado ao comando e às ordens do empregador (LENUZZA, 2007).

Existe uma sujeição do empregado ao poder diretivo e disciplinar conferido ao empregador, pelo fato de ter colocado à disposição deste a sua força de trabalho por meio da contraprestação de salário. O teletrabalho pode esbarrar em falsas autonomias ou em pseudossubordinações, dificultando, assim, a possibilidade do nítido reconhecimento da relação de emprego. Explica Martins (2003) ${ }^{9}$ que, no teletrabalho, a subordinação costuma ser rarefeita, pois há novas formas de subordinação, passando a existir a telessubordinação ou parassubordinação (DE MASI, 2000 apud WINTER, 2005, p. 89-94).

Com o advento do teletrabalho, a subordinação ficaria mitigada, todavia, o emprego da tecnologia não extinguiu o elemento da subordinação na relação de emprego. Ao contrário, intensificou a

9 Explica Martins (2003, p. 144): "Na telessubordinação, há subordinação a distância, porém mais tênue do que a normal [...] a parassubordinação seria uma variedade da relação de trabalho autônomo, [...] seria uma situação análoga à do trabalho dependente. É o reconhecimento jurídico de uma categoria de relação afim ao trabalho subordinado, com um resultado semelhante." 
submissão do empregado às ordens emanadas pelo empregador por meio de sistemas (OLIVEIRA, 2008), obrigando a reformulação da morfologia de "subordinação".

Aplicando-se o princípio da primazia da realidade e configurada a relação de emprego por meio da observação dos cinco elementos propostos pela legislação celetista, são devidos ao empregado, por parte do empregador, todos os direitos e deveres inerentes a essa relação contratual, constantes no artigo $7^{\circ}$ da Constituição Federal de 1988, da Consolidação das Leis Trabalhistas e leis pertinentes.

Ancorado nas ponderações destacadas, o próximo passo consiste em visualizar as vantagens e desvantagens dessa forma de vínculo.

\subsection{Vantagens e desvantagens do teletrabalho}

O teletrabalho, como todo resultado proveniente das inovações tecnológicas, acolhe vantagens e desvantagens. Dentre as vantagens, alinham-se algumas de interesse direto da empresa e do empregado, como diminuição de despesas com transporte, vestuário e combustível, aumento da produtividade, simplificação da fiscalização do trabalho, e racionalização de instalações, equipamentos e material de trabalho. Algumas vantagens são de interesse psicossocial do empregado, como liberação das tensões do tráfego na ida e volta do trabalho, supressão da rigidez de horário e liberdade para atendimento de interesses pessoais e familiares duranteo período de trabalho (PINTO; PAMPLONA FILHO, 2000).

A doutrina aponta como fator importante a possibilidade de o teletrabalho se estender a um contingente humano que, hoje em dia, enfrenta dificuldade em obter emprego formal, atuando como um meio hábil de contribuição para a diminuição da desigualdade de oportunidades, como é o caso dos trabalhadores com deficiência ${ }^{10}$.

\footnotetext{
10 Apontamos que o tema "teletrabalho como forma de inclusão ao trabalho das pessoas com deficiência" foi objeto de artigo apresentado em coautoria pelas articulistas do presente artigo no XX Encontro Nacional do CONPEDI, realizado nos dias 22, 23, 24 e 25 de junho de 2011, na cidade de Belo Horizonte-MG.
} 
O teletrabalho pode trazer de volta ao mercado diversos trabalhadores que poderiam ter dificuldades ou até mesmo ser discriminados em função de ineficiência temporária ou definitiva. Nessa perspectiva, pessoas com dificuldade de locomoção, profissionais com deficiências auditivas e visuais, entre outros, teriam novas oportunidades.

Importante salientar que, para o teletrabalho, não importa raça, sexo, idade, estado civil, deficiência, condição social e econômica, barreiras muito comuns para o mercado tradicional de trabalho, pois tal instituição deve ser capaz de produzir tanto empregos altamente especializados quanto aqueles que demandam menos especialização, atingindo, portanto, uma grande quantidade de trabalhadores, inclusive os que hoje se encontram excluídos do mercado de trabalho.

No entanto, as vantagens podem revestir-se de desvantagens. Por exemplo, o teletrabalho pode significar diminuição do tempo livre, isolamento social, redução da distinção entre vida profissional e vida particular, e menores possibilidades de ascensão profissional (WINTER, 2005). Além disso, há a quebra de privacidade, face às características dos sistemas de computação. Há que se cuidar desse aspecto, porque existe risco de atentar contra as liberdades individuais e o direito de privacidade, garantido a todas as pessoas (FRANCO FILHO, 1998).

O teletrabalho impõe uma mudança não só nos aspectos econômico, jurídico e social, mas também no cultural, à medida que o fenômeno da globalização, que está a aproximar os povos e a eliminar barreiras, abrange o teletrabalho e é por meio dele que se deve buscar os instrumentos necessários para adaptar as empresas e os trabalhadores a essa irreversível realidade.

A partir disso, observa-se que, como resposta à necessidade de se conferir efetividade ao direito ao trabalho, o teletrabalho apresenta-se como instrumento garantidor da possibilidade de inserção de um grupo de trabalhadores na vida ativa e no mercado de trabalho. No próximo tópico, analisamos se, sob a perspectiva social, o teletrabalho de fato inclui ou exclui. 


\section{O teletrabalho como forma de acesso das pessoas ao mercado de trabalho: inclusão social ou infoexclusão?}

O teletrabalho surge, para alguns trabalhadores, como uma chance de se inserir ou de retornar ao mercado de trabalho por meio do uso das tecnologias de informação e comunicação. Assim, ele atende às novas exigências do mundo globalizado, pela sua natureza flexível e peculiar, capaz de gerar empregos altamente especializados e de menor especialização, atraindo um grande contingente de trabalhadores.

Para evitar que as pessoas sejam marginalizadas e excluídas do contexto social e do mercado de trabalho, é necessário estabelecer mecanismos que garantam a dignidade da pessoa humana e a efetividade do princípio da igualdade. A efetividade do direito ao trabalho faz com que a dignidade humana assuma nítido conteúdo social, na medida em que a criação de melhores condições de vida é benéfica não somente para o indivíduo em seu âmbito particular, mas para o conjunto da sociedade (LEDUR, 1998).

Marques (2007) advoga que o valor social do trabalho é o elemento principal de toda norma pertencente a um Estado Democrático de Direito, pois este só existe porque há trabalho humano. Alguém só pode adquirir um bem e dizer "é meu" porque há trabalho humano. $\mathrm{O}$ autor destaca que o trabalho, por si, não é um conceito econômico, mas um elemento da existência humana. As pessoas trabalham para, muito além de prover sua subsistência, suprir suas demandas, não apenas materiais, mas também existenciais. O trabalho não é, portanto, apenas um elemento de produção. É bem mais do que isso. É algo que valoriza o ser humano e lhe traz dignidade, além, claro, do sustento. Por isso, deve ser visto, antes de tudo, como ligado de forma umbilical à dignidade da pessoa humana. Valorizar o trabalho significa valorizar a pessoa humana na condição de cidadão ativo na sociedade.

A experiência demonstra que, se aplicado corretamente, o teletrabalho pode constituir uma oportunidade de trabalho, entretanto, isso não significa que seja a solução mágica para os problemas de 
inserção das pessoas no mercado de trabalho. Nesse tema, o importante é o acesso ao trabalho e o problema fundamental é a qualidade do trabalho realizado, e não o tipo de pessoa que o realiza.

Diz-se que o teletrabalho não pode ser objeto de infoexclusão. 0 caminho para a inserção das pessoas no mercado de trabalho também pode ser pelo uso das tecnologias da informação e comunicação, com o objetivo de evitar o deslocamento casa-trabalho e vice-versa. Isso pode causar um efeito indesejado: a exclusão social, justamente por limitar a integração da pessoa na comunidade de trabalho. Não se deve pretender, com o teletrabalho, a clausura das pessoas, mas meios para que elas possam desenvolver-se com dignidade.

\section{Conclusão}

A sociedade da informação esbarra, à medida que cresce, num imenso desafio: precisa universalizar-se, democratizar-se, sob pena de reproduzir e perpetuar os velhos limites de um mundo historicamente desigual. Este artigo buscou examinar aspectos relacionados ao uso das tecnologias da informação e comunicação como instrumentos de redução das desigualdades sociais, em especial quanto ao uso do teletrabalho como forma de inserção no mercado de trabalho.

A premissa de que é por meio do trabalho que a pessoa alcança sua dignidade é importante, na medida em que os indivíduos, participando ativamente da vida em sociedade, ficam reconhecidos como sujeitos de direitos e deveres e são considerados positivamente dentro de suas diferenças. $O$ alicerce de todos os direitos constitucionalmente conferidos encontra-se no princípio da igualdade e da dignidade da pessoa humana.

Na sequência, a presente pesquisa debateu se o teletrabalho, além de prover a subsistência da pessoa humana, não pode tornar-se um fator de exclusão social face ao uso das novas tecnologias como ferramenta de trabalho, as quais não mais obrigam o trabalhador ao deslocamento casa-trabalho e vice-versa. 
Ao final, concluiu-se que dessa modalidade laboral não se deve esperar o enclausuramento do indivíduo, e sim uma maior possibilidade de convivência familiar, autonomia e gestão do tempo laboral e pessoal. Vantagens essas que, se constatadas, solidificam o que se conhece por valor social do trabalho, elemento ligado de forma umbilical à dignidade da pessoa humana.

\section{Referências}

BARROS, Alice Monteiro de. Curso de direito do trabalho. 5. ed. rev. e ampl. São Paulo: LTr, 2009.

DE MASI, Domenico. O futuro do trabalho: fadiga e ócio na sociedade pós-industrial. Rio de Janeiro: J. Olímpio, 1999.

DE MASI, Domenico. O ócio criativo. Tradução de Lea Manzi. Rio de Janeiro: Sextante, 2000.

FINCATO, Denise Pires. Teletrabalho: uma análise juslaboral. Revista Justiça do Trabalho, Porto Alegre, n. 236, p. 40-56, ago. 2003.

FONSECA, Ricardo Tadeu Marques da. 0 trabalho da pessoa com deficiência: lapidação dos direitos humanos: o direito do trabalho, uma ação afirmativa. São Paulo: Ltr, 2006.

FRANCO FILHO, Georgenor de Sousa. Globalização e desemprego: mudanças nas relações de trabalho. São Paulo: LTr, 1998.

FRIEDMAN, Thomas L. O mundo é plano: o mundo globalizado no século XXI. 3. ed. Rio de Janeiro: Objetiva, 2009.

GBEZO, Bernard E. Otro modo de trabajar: la revolución del teletrabajo. Trabajo: Revista da OIT, n. 14, p. 4-7, dez. 1995.

GÓES, Mauricio de Carvalho. A equiparação salarial como instrumento garantidor da isonomia nos contratos de emprego. Porto Alegre: Verbo Jurídico, 2009.

GOLDFARB, Cibelle Linero. Pessoas portadoras de deficiência e a relação de emprego: o sistema de cotas no Brasil. Curitiba: Juruá, 2009. 
JARDIM, Carla Carrara da Silva. O teletrabalho e suas atuais modalidades. São Paulo: LTr, 2003.

LEDUR, José Felipe. A realização do direito ao trabalho. Porto Alegre: Fabris, 1998.

LENUZZA, Letícia Maria Emanuelli. Teletrabalho: a tecnologia gerando uma nova forma de trabalho. 2007. 93 f. Dissertação (Mestrado em Concentração: Relações de Trabalho) - Programa de Pós-graduação em Direito, Universidade Federal de Caxias do Sul, Caxias do Sul, 2007.

MARQUES, Rafael da Silva. O valor social do trabalho na ordem econômica. Cadernos da ANAMATRA IV, Porto Alegre, n. 3, abr./jun.. 2007. Disponível em: <http://www.amatra4.org.br/publicacoes/cadernos/ caderno-03?start=3> Acesso em: 22 maio 2013.

MARQUES, Rafael da Silva. O valor social do trabalho na ordem econômica, na Constituição brasileira de 1988. São Paulo: LTr, 2007.

MARTINS, Sérgio Pinto. Comentários à CLT. 12. ed. São Paulo: Atlas, 2008.

MARTINS, Sérgio Pinto. Direito do trabalho. 17. ed. São Paulo: Atlas, 2003.

MARTINS, Sérgio Pinto. Direitos fundamentais trabalhistas. São Paulo: Atlas, 2008.

NILLES, Jack M. Fazendo do teletrabalho uma realidade. São Paulo: Futura, 1997.

OLIVEIRA, Cristiano de. O contrato do teletrabalhador. Justiça do trabalho, Porto Alegre, v. 25, n. 289, p. 23-29, jan. 2008.

PEDREIRA, José Pinho. O teletrabalho. Revista LTr, São Paulo, v. 64, n. 5 , p. 583-587, maio 2000.

PEZZELLA, Maria Cristina Cereser; BUBLITZ, Michelle Dias. Sociedade da informação: teletrabalho como forma de inclusão ao trabalho das pessoas com deficiência. In: ENCONTRO NACIONAL DO CONPEDI, 20., 2011, Belo Horizonte. Anais... Belo Horizonte: Fumec, 2011. p. 4823-4851. 
PINO ESTRADA, Manuel Martin. O teletrabalho: breve análise jurídica. Justiça do Trabalho, Porto Alegre, v. 248, p. 49-65, 2004.

PINTO, José Augusto Rodrigues; PAMPLONA FILHO, Rodolfo. Repertório de conceitos trabalhistas: direito individual. São Paulo: LTr, 2000. v. 1.

PODLECH, Adalbert. Anmerkungen zu Art. 1 Abs. I Grundgesetz. In: WASSERMANN, R. (Org.). Kommentar zum Grundgesetz für die Bundesrepublik Deutschland (Alternativkommentar). 2. ed. Neuwied: Luchterhand, 1989. v. II.

QUEIROZ JUNIOR, Hermano. Os direitos fundamentais dos trabalhadores na Constituição de 1988. São Paulo: LTr, 2006.

ROMITA, Arion Sayão. Direitos fundamentais nas relações de trabalho. 2. ed. rev. e aum. São Paulo: LTr, 2007.

SARLET, Ingo Wolfgang. Dignidade da pessoa humana e direitos fundamentais na Constituição Federal de 1988. 9.ed. Rev. atual. Porto Alegre: Livraria do Advogado, 2011.

SARLET, Ingo Wolfgang. A eficácia dos direitos fundamentais: uma teoria geral dos direitos fundamentais na perspectiva constitucional. 10. ed. rev. atual. e ampl. Porto Alegre: Livraria do Advogado, 2010.

SILVA, Frederico Silveira e. O teletrabalho como novo meio de laborar e sua compatibilidade com o ordenamento jurídico. Revista CEJ, Brasília, DF, n. 27, p. 102-109, 2004.

SILVA, Frederico Silveira e. O teletrabalho como novo meio de laborar e sua compatibilidade com o ordenamento jurídico brasileiro. Jus Navigandi, Teresina, ano 8, n. 382, 24 jul. 2004. Disponível em: <http:// jus2.uol.com.br/doutrina/texto.asp?id=54 99>. Acesso em: 17 ago. 2009.

SILVA NETO, Manoel Jorge e. Direitos fundamentais e o contrato de trabalho. São Paulo: LTr, 2005.

SILVA NETO, Manoel Jorge e. Proteção constitucional dos interesses trabalhistas difusos, coletivos e individuais homogêneos. São Paulo: LTr, 2001. 
SOARES JÚNIOR, Abeilar dos Santos. Configurações jurídicas do tele-emprego. Jus Navigandi, Teresina, ano 8, n. 475, 25 out. 2004. Disponível em: <http://jus2.uol.com.br/doutrina/texto.asp?id=5836>. Acesso em: 15 set. 2009.

VILLEY, Michel. Estudios en torno a la nocion de derecho subjetivo. Tradução de Alejandro Guzmán Brito e outros. Valparaíso: Ediciones Universitarias de Valparaiso, 1976.

WINTER, Vera Regina Loureiro. Teletrabalho: uma forma alternativa de emprego. São Paulo: LTr, 2005.

Recebido em: 00/11/13

Aprovado em: 00/12/13 